\title{
The DNA puff BhB10-1 gene is differentially expressed in various tissues of Bradysia hygida late larvae and constitutively transcribed in transgenic Drosophila
}

\section{N. Monesi, \\ J.F. Sousa and \\ M.L. Paçó-Larson}

\begin{abstract}
D epartamento de Biologia Celular e M olecular e Bioagentes Patogênicos, Faculdade de Medicina de Ribeirão Preto, Universidade de São Paulo, Ribeirão Preto, SP, Brasil
\end{abstract}

\section{Correspondence \\ M.L. Paçó-Larson \\ Departamento de Biologia Celular e Molecular e Bioagentes Patogênicos FMRP, USP \\ Av. Bandeirantes, 3900 14049-900 Ribeirão Preto, SP Brasil \\ Fax: + 55-16-633-1786 \\ E-mail: mlplarso@fmrp.usp.br \\ Research supported by FAPESP (No. 96/9378-9). J.F. Sousa was the recipient of a CAPES fellowship, $N$. Monesi was the recipient of a postdoctoral fellowship from FAPESP (No. 96/06418-0), and M.L. Paçó-Larson was the recipient of a CNPq fellowship (No. 520573/98-6). \\ The present address of $\mathrm{N}$. M onesi is Departamento de Análises Clínicas, Toxicológicas e Bromatológicas, Faculdade de Ciências Farmacêuticas de Ribeirão Preto, USP, 14040-903 Ribeirão Preto, SP, Brasil.}

Received O ctober 31, 2000 Accepted April 10, 2001

\begin{abstract}
We extended the characterization of the DNA puff BhB10-1 gene of Bradysia hygida by showing that, although its mRNA is detected only at the end of the fourth larval instar, BhB10-1 expression is not restricted to the salivary gland, the tissue in which this gene is amplified. Different amounts of BhB10-1 mRNA were detected in other larval tissues such as gut, Malpighian tubules, fat body, brain and cuticle, suggesting that this gene is expressed differentially in the various tissues analyzed. Analysis of transgenic Drosophila carrying the $B h B 10-1$ transcription unit and flanking sequences revealed that the tested fragment promotes transcription in a constitutive manner. We suggest that either cis-regulatory elements are missing in the transgene or factors that temporally regulate the $B h B 10-1$ gene in $B$. hygida are not conserved in Drosophila.
\end{abstract}

\author{
Key words \\ - DNA puff \\ - Gene expression \\ - Development \\ - Ecdysone \\ - Transgenic Drosophila
}

\section{Introduction}

DNA puffs are formed at discrete sites in the polytene chromosomes of sciarid salivary gland cells during the last larval instar. The molecular characterization of these genomic regions has demonstrated that they are sites of developmentally regulated gene amplification and transcription controlled by ecdysone (for a review, see Refs. 1-3).

Two groups of DNA puffs can be distinguished based on the time of puff expansion in Bradysia hygida. The first group expands around $26 \mathrm{~h}$ before the pupal molt (stage E7). Sixteen hours later, when the first group of puffs has regressed, the second group of
DNA puffs reaches its maximum expansion. The only exception is the DNA puff B10 in which maximal expansion occurs during an intermediate time period between the first and second groups (4). A 2-kb EcoRI fragment from this puff, which contains the entire BhB10-1 transcription unit, is amplified about 10 -fold in the salivary gland during puff formation. The BhB10-1 gene is complementary to two mRNA species of about 1.3 and $1.1 \mathrm{~kb}$, whose expression accompanies the formation of DNA puff B10. The 1.3-kb mRNA species is initially detected at E7; however, $8 \mathrm{~h}$ later both mRNA species are present in the gland, and $16 \mathrm{~h}$ later only small amounts of the 1.1-kb mRNA species are 
detected (5). Further characterization of the BhB10-1 transcripts has demonstrated that the 1.3-kb mRNA species undergoes a poly A tail shortening process, giving rise to the 1.1-kb transcript, indicating that the BhB10-1 gene is also regulated at the post-transcriptional level (6). In immunoblots, the BhB10-1 protein has been identified as a $23-\mathrm{kDa}$ polypeptide present in the salivary gland and in the saliva of larvae at the time when the DNA puff B10 is formed (6).

The analysis of transgenic lineages of Drosophila carrying promoter sequences of the II/9-1 gene of Sciara coprophila and the BhC4-1 gene of B. hygida has indicated that the factors necessary for tissue-specific and developmentally regulated expression of sciarid DNA puff genes may be conserved in Drosophila $(7,8)$. The transformed sequences so far tested are not amplified in the salivary gland of transgenic Drosophila, indicating that amplification and transcription of DNA puff genes are processes that can be uncoupled $(7,8)$.

In the present study, we have extended the characterization of the DNA puff B10 gene of $B$. hygida by showing that the $B h B 10$ 1 mRNA expression is induced at the end of the fourth larval instar in other larval tissues in addition to the salivary gland, the tissue in which the gene is amplified and the puff is formed. We have also analyzed the expression of the BhB10-1 gene in six independent Drosophila transgenic lineages transformed with the 2-kb EcoRI genomic fragment from the B10 DNA puff, which contains the BhB10-1 transcription unit and flanking sequences. We show that in these transgenic lineages the $B h B 10-1$ gene is ubiquitously expressed, suggesting that $B h B 10-1$ regulation is not maintained in Drosophila.

\section{Material and Methods}

\section{Bradysia hygida}

Larval tissues were obtained from female larvae of a laboratory culture kept at $20^{\circ} \mathrm{C}$ (9). Larval staging during the fourth larval instar, from stage E1 to E7, was based on eye spot pattern as described previously (4). Stage E1 occurs prior to DNA puff expansion and stage E7 corresponds to the time of the first DNA puff group formation. The DNA puff B10 is maximally expanded $8 \mathrm{~h}$ after E7. Whole animals were frozen in liquid nitrogen after staging, while larval tissues were dissected in insect saline and immediately frozen in dry ice/ethanol baths. Whole animals or tissues were kept at $-80^{\circ} \mathrm{C}$ until processing.

\section{Drosophila melanogaster}

Drosophila lineages were kept at $25^{\circ} \mathrm{C}$. Embryo collection and larval staging were as described by Ashburner (10). The time of puparium formation was used as the reference point for staging prepupae and pupae. White prepupae were removed from the food vials and maintained on Petri dishes on a moistened piece of filter paper. After the number of hours indicated for each experiment the animals were frozen in liquid nitrogen. For tissue collection, animals were dissected in insect saline solution and frozen in dry ice/ethanol.

\section{Constructs and P-element transformation}

The B1 construct consists of an $\sim 2-\mathrm{kb}$ $E c o$ RI genomic fragment from DNA puff B10 of B. hygida (5), inserted into the $P$ element vector pCaSpeR 4 (11). The puff B10 fragment contains the BhB10-1 transcription unit $(876 \mathrm{bp}$ ) plus $816 \mathrm{bp}$ of upstream flanking sequences and 241 bp of downstream flanking sequences. The B1 construct was injected into embryos of the Drosophila melanogaster $y, w$ strain, together with the helper plasmid phs $\pi$ (12), at DNA concentrations of 0.5 and $0.1 \mu \mathrm{g} / \mathrm{ml}$, respectively. $P$-element transformation was carried out following standard procedures $(13,14)$. 
Surviving G0 flies were mated individually with the parental strain and the resulting independent G1 transformants were used to establish homozygous lineages.

\section{RNA extraction}

Homogenization of frozen animals or tissues was performed in lysis buffer $(10 \mathrm{mM}$ Tris-HCl, $\mathrm{pH}$ 9.0, 2\% SDS, $50 \mathrm{mM}$ EDTA, $5 \%$ ethanol). After homogenization, total RNA was extracted by adding 10 volumes of Trizol, following the manufacturer's protocol (Gibco-BRL, Rockville, MD, USA). Total RNA concentrations were estimated by absorbance at $260 \mathrm{~nm}$, assuming that $40 \mu \mathrm{g} /$ ml RNA has an absorbance of 1.0.

\section{Analysis of BhB10-1 mRNA by Northern blot hybridization}

Total RNA was fractionated on denaturing $1 \%$ agarose/formaldehyde gels (15) and blotted to a nylon membrane (Hybond N, Amersham Pharmacia Biotech, Uppsala, Sweden). Probes were labeled with $\left[\alpha^{32} \mathrm{P}\right]-$ dCTP by random primer reactions. Hybridization was performed at $65^{\circ} \mathrm{C}$ in Church's buffer (1\% BSA, 1 mM EDTA, 7\% SDS, 0.5 $\left.\mathrm{M} \mathrm{NaHPO}_{4}, \mathrm{pH} 7.5\right)$. The final wash was 0.1 $\mathrm{X} \mathrm{SSC}$ and $0.2 \%$ SDS at $65^{\circ} \mathrm{C}$.

\section{Ribonuclease protection assays}

Ribonuclease protection assays (RPAs) were performed using the RPA II kit (Ambion, Austin, TX, USA), according to manufacturer instructions. The BhB10-1 probe was a 316-bp fragment from the BhB10-1 coding sequence (6). The actin probe consisted of a 650-bp fragment containing 5 ' noncoding and coding sequences of the Drosophila actin gene (16). The ribosomal probe was a 190-bp fragment from $B$. hygida 28S ribosomal DNA (NCBI accession number AF147103). After linearization of the template, in vitro transcription was performed in the presence of $\left[\alpha^{32} \mathrm{P}\right]-\mathrm{UTP}$, using the MAXIscript T7/T3 kit (Ambion). The resulting BhB10-1 transcript was $411 \mathrm{bp}$ long (316 bp of BhB10-1 sequences plus 95 $\mathrm{bp}$ from plasmid sequences), the resulting actin transcript was $701 \mathrm{bp}$ long (650 bp of actin sequences plus $51 \mathrm{bp}$ from plasmid sequences) and the resulting $B$. hygida ribosomal probe was $285 \mathrm{bp}$ long (190 bp of rDNA sequences plus $95 \mathrm{bp}$ from plasmid sequences). The in vitro transcribed probes were gel purified before use. The protected fragments were electrophoresed on $6 \%$ acrylamide/8 M urea gels.

\section{Results}

\section{Developmental pattern of BhB10-1 gene expression in B. hygida}

In order to extend the characterization of BhB10-1 gene expression in B. hygida we performed RPAs in whole animals at different developmental times and in salivary glands and carcasses of larvae at stage E7 + $8 \mathrm{~h}$ when the gene is abundantly transcribed in the salivary gland (5). The probe complementary to the BhB10-1 mRNA is $411 \mathrm{bp}$ long and results in the protection of a 316-bp fragment. As can be seen in Figure 1, the hybridization of total RNA from embryos, whole second- and third-instar larvae, whole fourth-instar larvae at stages E1, E7 and E7 + $8 \mathrm{~h}$, whole pupae, and whole adults resulted in the protection of the 316-bp fragment only in samples obtained from late fourth-instar larvae (E7, E7 +8 h) and early pupae. In agreement with previous data on the expression of BhB10-1 mRNA in B. hygida salivary glands (5), the highest transcript levels were found at stage $\mathrm{E} 7+8$ h, i.e., coinciding with the formation of the DNA puff B10 in the salivary gland polytene chromosomes (Figure 1). Unexpectedly, we also detected high levels of BhB10-1 mRNA in total RNA extracted from carcasses of larvae at stage $\mathrm{E} 7+8 \mathrm{~h}$ (Figure 1), suggesting that this gene 
is also expressed in larval tissues other than the salivary gland at the time when the corresponding DNA puff is formed.

In order to further investigate the expression of the BhB10-1 gene, we analyzed its mRNA in Northern blots containing total RNA of different tissues of larvae at stages E1 and E7 +8 h. As shown in Figure 2, the BhB10-1 mRNA is detected only at stage E7 $+8 \mathrm{~h}$ and is present in different amounts in brain, gut, Malpighian tubules, fat body, integument, and salivary glands of larvae at stage E7 $+8 \mathrm{~h}$. These results show for the first time that the transcript of a DNA puff gene is expressed in other tissues besides the salivary gland, tissue in which the gene is specifically amplified.

\section{BhB10-1 gene expression in transgenic Drosophila}

In order to obtain a system to investigate molecular mechanisms that regulate the BhB10-1 gene, we obtained Drosophila transgenic lineages carrying a 2-kb genomic fragment from DNA puff B10. This fragment contains the entire BhB10-1 transcription unit, 816 bp of upstream flanking sequences, and $241 \mathrm{bp}$ of downstream flanking sequences. Six independent transgenic lineages, PB1-4, PB1-5, PB1-6, PB1-9, PB1-28 and PB1-33, were obtained. With the exception of lineage PB1-5, which harbors two copies of the transgene, all the other lineages contain a single copy of the transformed construct, as verified by Southern blot analysis (data not shown). The six transgene homozygous lineages are viable and we did not notice any morphological or behavioral changes.

BhB10-1 expression in the transgenic lineages was investigated by RPAs. The probe complementary to BhB10-1 mRNA resulted in the protection of a 316-bp fragment which was detected in lineage PB1-33, but was absent in the $y, w$ strain, indicating that there is no endogenous expression of the trans- gene in the parental strain (Figure 3, lanes B10). The antisense actin probe, employed as a loading control, is $650 \mathrm{bp}$ long and results in the protection of a 260-bp fragment (Figure 3, lanes act).

The BhB10-1 mRNA is ubiquitously expressed in lineage PB1-33. It is detected in embryos, first-, second- and third-instar larvae $(\mathrm{L} 1 / 2, \mathrm{~L} 3)$, during the prepupal $(0,+3$, +6 , and $+9 \mathrm{~h}$ ), and pupal period (24 h pupa) and in adults of both sexes (Figure 3 ). This pattern of expression was demonstrated in the other five independently obtained lineages (data not shown), showing that the 2$\mathrm{kb}$ fragment of $B$. hygida is able to drive transcription of the BhB10-1 gene in Drosophila.

In order to determine whether the BhB10-1 gene was expressed differentially in the salivary glands and carcasses of the transgenic Drosophila, steady-state expression levels were analyzed in salivary glands and carcasses from third-instar larvae, and prepupae at $0,+3,+6$, and +9 h using RPAs (Figure 4). In the PB1-33 lineage, the BhB10-1 mRNA was expressed at similar levels in the salivary gland and in carcasses throughout the developmental period analyzed (Figure 4). The stronger signal in carcasses was due to the different amounts of total RNA from carcasses employed in the assay $(30 \mu \mathrm{g})$ as opposed to those employed for salivary gland samples (3 $\mu \mathrm{g})$. Similar results were obtained for another independent transgenic lineage, PB1-5.

Taken together, the results obtained from the analysis of transgenic Drosophila lineages transformed with the $2-\mathrm{kb}$ fragment from DNA puff B10 of $B$. hygida indicate that the transformed fragment contains elements which are able to promote $B h B 10-1$ transcription. However, in contrast to $B$. hygida, transgenic Drosophila express the BhB10-1 mRNA in a constitutive manner throughout development, regardless of stage or tissue. 


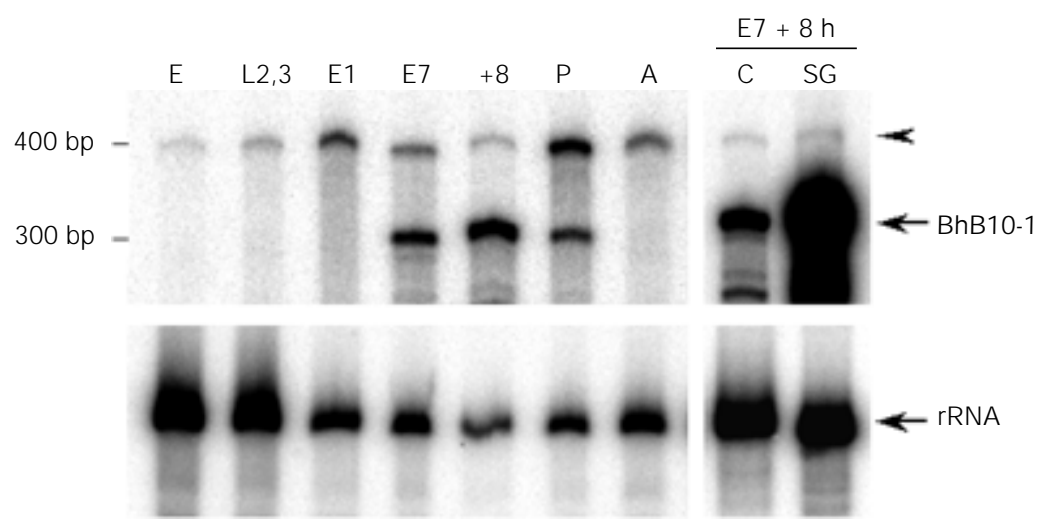

Figure 1. Developmental pattern of expression of the BhB10-1 gene in Bradysia hygida. Upper autoradiograms, $50 \mu \mathrm{g}$ of total RNA extracted from embryos (E), second- and third-instar larvae $(L 2,3)$, fourth-instar larvae at stage before DNA puff formation (E1) and adults (A); $2.5 \mu \mathrm{g}$ of total RNA from whole fourth-instar lanvae at the time when the first group of DNA puffs expands (E7), whole fourthinstar larvae (+8) or carcasses (C) from larvae $8 \mathrm{~h}$ after $\mathrm{E} 7$ when puff $\mathrm{B} 10$ is maximally expanded and young pupae $(\mathrm{P})$, and $0.25 \mu \mathrm{g}$ of total RNA extracted from salivary glands (SG) of larvae at stage E7 + $8 \mathrm{~h}$. The RNAs were analyzed with a ribonuclease protection assay (RPA) with an antisense probe complementary to the BhB10-1 gene. The protected fragment is $316 \mathrm{bp}$ long (BhB10-1, arrow). The higher molecular weight fragment indicated by the arrowhead is the undigested BhB10-1 probe. Lower autoradiograms, 10 ng of total RNA extracted from the same developmental stages and tissues as described above was analyzed by RPA with an antisense probe complementary to the $28 \mathrm{~S}$ rRNA of B. hygida. Due to the abundance of the rRNA it was necessary to independently hybridize a dilution of the same RNA samples (10 ng) used in the above RPA with the rRNA probe employed as control for the amount of total RNA in the assay. The protected fragment is 190 bp long (rRNA, arrow). The migration of the RNA size markers is indicated on the left. The left side autoradiograms were exposed for 5 days, whereas the autoradiograms on the right side were exposed for 8 days, which accounts for the stronger signal in lanes (E7 + 8 h C/E7 +8 h SG).

E1

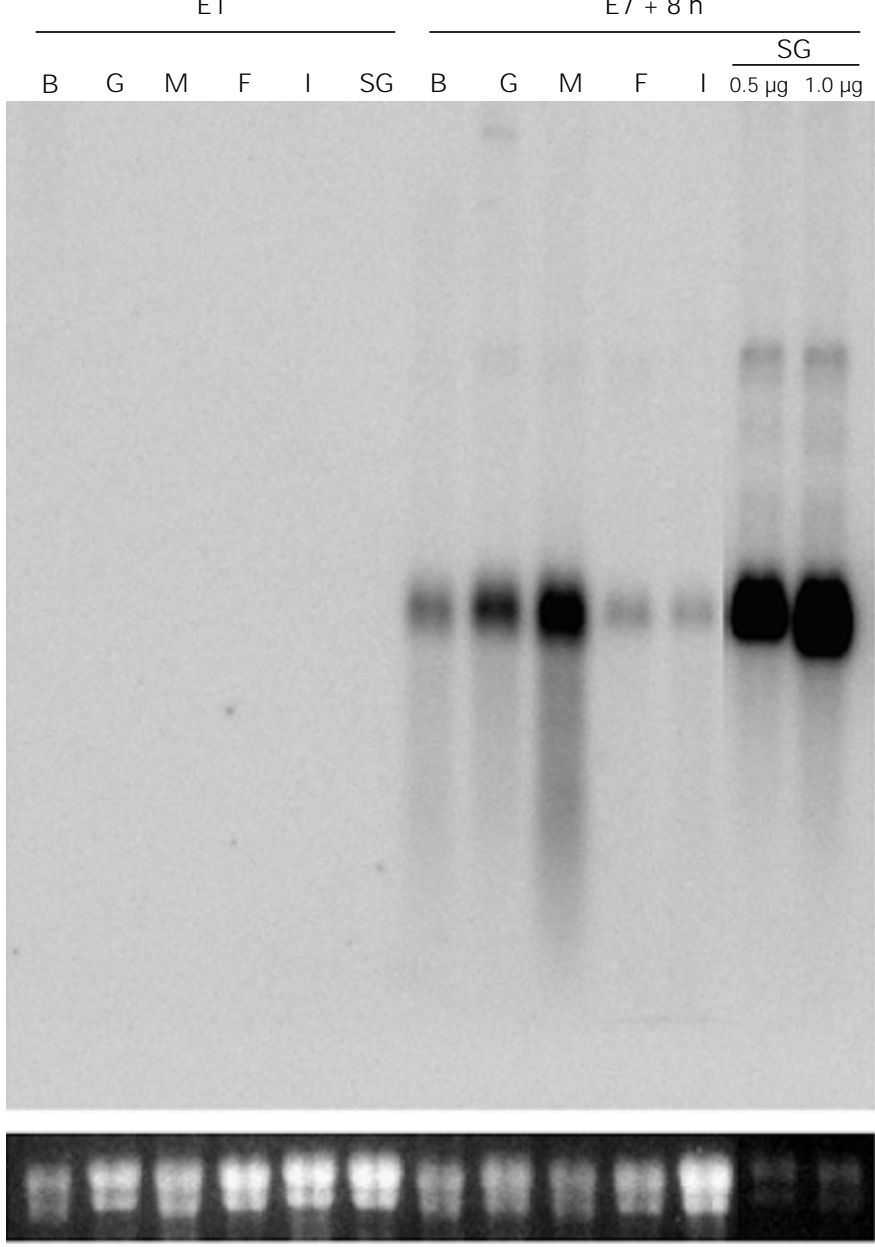

285

185

BhB10-1

rRNA
Figure 2. Northem blot characterization of BhB10-1 mRNA expression in different tissues at the end of the fourth larval instar of Bradysia hygida. Upper autoradiogram, Northern blot after hybridization with the 2-kb genomic fragment from DNA puff B10, which contains the BhB10-1 transcription unit (5). The lanes contain about $7 \mu \mathrm{g}$ of total RNA extracted from brain (B), gut (G), Malpighian tubules $(M)$, fat body (F) and integument (I) of lanvae at a stage before puff formation (lanes E1) and larvae at the stage when puff B10 is maximally expanded (lanes E7 + 8 h), about $7 \mu \mathrm{g}$ of total RNA extracted from salivary glands (SG) of larvae at E1, and $0.5 \mu \mathrm{g}$ and $1.0 \mu \mathrm{g}$ of total RNA extracted from salivary glands of larvae at E7 + $8 \mathrm{~h}$ (lanes SG). The arrow points to the BhB10-1 mRNAs ranging from 1.3 to $1.1 \mathrm{~kb}$. The extra bands of higher molecular weight are not reproducible. The lower picture is an image of the gel before blotting to show the loading of the lanes. The migration of the 28 and 185 mammalian ribosomal RNA, employed as molecular size markers, is indicated by asterisks on the right. 
Figure 3. Developmental pattern of expression of BhB10-1 mRNA in the transgenic lineage PB1-33. Forty micrograms of total RNA extracted from embryos $(E)$, firstand second-instar larvae $(\mathrm{L} 1,2)$, third-instar lanvae (L3), prepupae at $0,3,6$, and $9 \mathrm{~h}(0,+3,+6$, and $+9 \mathrm{~h})$, pupae at $24 \mathrm{~h}(24 \mathrm{~h})$, adult males (M) and adult females (F) from transgenic lineage PB1-33 was analyzed by RPA using two different radiolabeled probes. Probe (B10) is a 411-bp long RNA complementary to the BhB10-1 gene which results in the protection of a 316-bp long fragment (BhB10-1, arrow). Probe (act) is a 700-bp long RNA complementary to the Drosophila actin gene, and the protected fragment is 260 bp long (actin, arrow). In

lanes $y, w$, a mixture containing equal amounts of total RNA extracted from prepupae at $0,3,6$ and $9 \mathrm{~h}$ from the parental strain $y, w$ was separately hybridized with each of the probes (y,w/B10 and y,w/act). Note the absence of endogenous BhB10-1 expression in the parental strain $y, w$. In lanes PB133/B10 and PB1-33/act, $40 \mu \mathrm{g}$ of a mixture containing equal amounts of total RNA extracted from prepupae at $0,3,6$ and $9 \mathrm{~h}$ from the transgenic lineage PB1-33 was hybridized with probes (B10) or (act) as indicated. In lanes yeast RNA, $10 \mu \mathrm{g}$ of yeast RNA (negative control) was hybridized with the same amounts of probes (B10) and (act) that were employed in the assay and treated (B10/+, act/+) or not (B10/-, act/-) with ribonuclease. Lanes (-) show the size of the unprotected probes. The migration of the RNA size markers is indicated on the right.
Figure 4. The BhB10-1 mRNA is expressed in a constitutive manner in the salivary gland and in carcasses of late third-instar larvae and prepupae of the transgenic lineage PB1-33. Autoradiogram of an RPA in which $3 \mu \mathrm{g}$ of total RNA extracted from salivary glands of third-instar lanvae (L3) and prepupae at $0,3,6$, and $9 \mathrm{~h}$ $(0,+3,+6$, and $+9 \mathrm{~h})$, or $30 \mu \mathrm{g}$ of total RNA extracted from carcasses of third-instar larvae and prepupae at $0,3,6$, and $9 \mathrm{~h}$ from the transgenic lineage PB1-33 was simultaneously hybridized with two radiolabeled probes. Probe (B10) is a 411-bp long RNA complementary to the BhB10-1 gene and the protected fragment is $316 \mathrm{bp}$ long (BhB10-1, arrow). Probe (act) is a 700-bp long RNA

complementary to the Drosophila actin gene and the protected fragment is about $260 \mathrm{bp}$ long (actin, arrow). In lanes (whole prepupae), $30 \mu \mathrm{g}$ of a mixture containing equal amounts of total RNA extracted from whole prepupae at $0,3,6$ and $9 \mathrm{~h}$ from transgenic lineage PB1-33 was hybridized with probes (B10) or (act) as indicated. The migration of the RNA size markers is indicated on the right. 


\section{Discussion}

The developmentally regulated gene amplification that occurs in sciarid DNA puffs is generally interpreted as an evolutionarily selected mechanism which regulates the production of specific proteins required in large amounts during short periods of time (for a review, see Refs. 1-3). This view has been supported by the strict temporal correlation observed between amplification and activation of transcription of several DNA puff genes in the salivary glands of last-instar larvae (5,17-20), and implies a tissue-specific expression of the amplified genes. Our results showing that the transcription of an amplified DNA puff gene is not restricted to the larval salivary glands add a new perspective to this interpretation. The BhB10-1 mRNA is detected by Northern blot hybridization in various other tissues of $B$. hygida late larvae, albeit in lower amounts than in the salivary gland in which the gene is amplified (5).

The expression of BhB10-1 mRNA in larval tissues other than the salivary gland also has implications for the understanding of the biological role of the encoded protein. Although there are indications that DNA puff products constitute secretory polypeptides produced by the salivary gland $(6,21$ 23 ), the function of these proteins is still unknown. Comparison of DNA puff polypeptide sequences with protein data bases results in no significant matches with other known protein sequences, which places DNA puff proteins in a distinct class of proteins (24). In previous work we have identified the BhB10-1 gene product as a 23-kDa polypeptide in immunoblots of salivary glands from late larvae (6). However, using the same antibody we were unable to detect the 23$\mathrm{kDa}$ polypeptide in tissues other than the salivary gland (data not shown), which could be attributed to the absence of BhB10-1 protein in these tissues. Alternatively, the failure in detecting $\mathrm{BhB} 10-1$ protein in other larval tissues could be due to the presence of lower amounts of the protein in these tissues. Favoring this last possibility is the observation that the $\mathrm{BhB10}-1$ protein is detected in the salivary gland regions $\mathrm{S} 1$ and $\mathrm{S} 3$, but not in the $\mathrm{S} 2$ region (6). In the gland region $\mathrm{S} 2$, as in the other larval tissues analyzed in the present study, BhB10-1 mRNA is present at much lower levels. Further investigation is needed to verify if the BhB10-1 protein is expressed in other larval tissues or if the regulation of the $B h B 10-1$ gene also includes mechanisms that restrict mRNA translation to the salivary gland.

The observation that the BhB10-1 mRNA is detected at the same time in all tissues of late larvae analyzed suggests that the activation of the $B h B 10-1$ gene in these tissues is triggered by a common factor. A strong candidate for the activation of the $B h B 10-1$ gene at the end of the larval stage is ecdysone which is known to regulate DNA puffing in sciarid polytene chromosomes (25-28), and which induces DNA puff B10 formation when injected into early larvae (Fontes AM and Paçó-Larson ML, unpublished data). The observation of a peak in the ecdysteroid titer approximately $26 \mathrm{~h}$ before the pupal molt in B. hygida (Hartfelder K, Basso Jr LR and Paçó-Larson ML, unpublished data) also agrees with the idea that the induction of BhB10-1 mRNA expression in all tissues of late larvae may be regulated by ecdysone. The higher levels of BhB10-1 mRNA observed in the salivary gland are consistent with the presence of 10 -fold more copies of the $B h B 10-1$ gene in this tissue (5). However, since amplification of the BhB10-1 gene is detected only in the salivary gland (data not shown), the presence of different amounts of BhB10-1 mRNA in the tissues analyzed could suggest that the regulation of $B h B 10-1$ may involve tissue-specific regulators. Another possibility is that the $B h B 10-1$ mRNA half-life differs between the analyzed tissues. In this context it is interesting to note that previous studies have shown that 
the $B h B 10-1$ mRNA undergoes poly A tail shortening during development, suggesting that post-transcriptional controls as well as transcription activation are involved in the regulation of the $B h B 10-1$ gene (6). Taken together, the results presented here indicate that the control of the expression of amplified DNA puff genes is more complex than previously thought. A given gene can be expressed at different levels in various larval tissues at the time when the DNA puff is expanded in the salivary glands.

By employing Drosophila germ line transformation it has been shown that the factors involved in promoter regulation of the DNA puff gene $I I / 9-1$ of $S$. coprophila (7), and the BhC4-1 gene of B. hygida (8) are conserved between sciarids and Drosophila. In both cases, the promoter region needed for the temporal control of transcription in the salivary gland is not longer than $718 \mathrm{bp}$. In the present study, we show that a $2-\mathrm{kb}$ fragment containing the BhB10-1 transcription unit is capable of promoting constitutive transcription in Drosophila. However, the pattern of BhB10-1 mRNA expression in the transgenic Drosophila lineages is not the same as that observed in B. hygida. In the transgenic lineages, BhB10-1 mRNA was detected at all stages and in all tissues analyzed, suggesting that the factors involved in the regulation of the $B h B 10-1$ gene are not present in these animals. The absence of cis-regulatory elements in the transformed 2-kb fragment could explain these results. If this is the case, one might expect that the elements which activate $B$ B B10-1 transcription in B. hygida last-instar larvae would be located outside the tested fragment (positions $-817 \mathrm{bp}$ to $+1116 \mathrm{bp}$, determined in relation to the BhB10-1 gene transcription initiation site (6)). With this in mind, it is interesting to note that the BhB10-1 2-kb fragment contains an AT-rich sequence which is the only feature shared between the 5' flanking sequences of DNA puff genes (24), including the two DNA puff constructs which were expressed in a regulated manner in Drosophila $(7,8)$. Alternatively, the absence of an increase in the steady-state levels of BhB10-1 mRNA during the prepupal stage in transgenic Drosophila could be indicating that the factors involved in the induction of the BhB10-1 gene in B. hygida late larvae are not conserved between B. hygida and Drosophila. The analyses of transgenic lineages transformed with fragments including larger portions of $B h B 10-1$ gene-flanking regions will help to clarify this question.

\section{Acknowledgments}

We thank Cirlei A.V. Saraiva and Benedita O. de Souza for dedicated technical assistance, Valdir Mazzucatto for the maintenance of the Drosophila room and Cláudia R.M. Faggion and Domingos S.S. Filho for maintenance of the $B$. hygida culture. We also thank Dr. K. Hartfelder and Dr. R.J. Ward, from FFCLRP/USP, and Dr. Ann Stocker, from IB/USP, for reviewing the manuscript.

\section{References}

1. Lara FJ S, Stocker AJ \& Amabis J M (1991). DNA sequence amplification in sciarid flies: results and perspectives. Brazilian $\mathrm{J}$ ournal of Medical and Biological Research, 24: 233-248.

2. Gerbi SA, Liang C, Wu N, DiBartolomeis SM, Bienz-Tadmor B, Smith HS \& Umov FD (1993). DNA amplification in DNA puff II/9A of Sciara coprophila. Cold Spring Har- bor Symposia on Quantitative Biology, 57: 487-494.

3. Stocker AJ, Yokosawa J, Soares MA \& Cadavid EO (1996). DNA replication and amplification during the final cycle of polyteny in sciarid salivary gland chromosomes and their control by ecdysone. Ciência e Cultura, 48: 306-312.

4. Laicine EM, Alves MAR, de Almeida J C,
Rizzo E, Albernaz WC \& Sauaia H (1984). Development of DNA puffs and patterns of polypeptide synthesis in the salivary glands of Bradysia hygida. Chromosoma, 89: 280-284.

5. Fontes AM, de Almeida J C, Edstrom J E \& Paçó-Larson ML (1992). Cloning of a B-10 DNA puff sequence developmentally amplified and expressed in the salivary gland 
of Bradysia hygida. Brazilian J ournal of Medical and Biological Research, 25: 777780.

6. Fontes $\mathrm{AM}$, Conacci ME, Monesi N, de AlmeidaJ C \& Paçó-Larson ML (1999). The DNA puff BhB10-1 gene encodes a glycine-rich protein secreted by the late larvae salivary glands of Bradysia hygida. Gene, 231: 67-75.

7. Bienz-Tadmor B, Smith HS \& Gerbi SA (1991). The promoter of DNA puff II/9-1 of Sciara coprophila is inducible by ecdysone in late prepupal salivary glands of Drosophila melanogaster. Cell Regulation, 2: 875-888.

8. Monesi N, Jacobs-Lorena M \& PaçóLarson ML (1998). The DNA puff gene BhC4-1 of B. hygida is specifically transcribed in early prepupal salivary glands of Drosophila melanogaster. Chromosoma, 107: 559-569.

9. Sauaia $H$, Laicine EM \& Alves MAR (1971). Hydroxyurea-induced inhibition of DNA puff development in salivary gland chromosomes of Bradysia hygida. Chromosoma, 34: 129-151.

10. Ashburner MA (1989). Drosophila, A Laboratory Handbook. Cold Spring Harbor Laboratory Press, Cold Spring Harbor, NY.

11. Pirrotta V (1988). Vectors. A Survey of Molecular Cloning Vectors and their Uses. Butterworths, Boston and London.

12. Steller H \& Pirrotta V (1986). P transposons controlled by the heat shock promoter. Molecular and Cellular Biology, 6: 1640-1649.

13. Spradling AC \& Rubin GM (1982). Transposition of cloned P-elements into Drosophila germ line chromosomes. Science, 218: 341-347.
14. Rubin GM \& Spradling AC (1982). Genetic transformation of Drosophila with transposable element vectors. Science, 218 : 348-353.

15. Sambrook J, Fritsch EF \& Maniatis $T$ (1989). Molecular Cloning, A Laboratory Manual. 2nd edn. Cold Spring Harbor Laboratory Press, Cold Spring Harbor, NY.

16. Fyrberg EA, Bond BJ , Hershey ND, M ixter KS \& Davidson N (1981). The actin genes of Drosophila: protein coding regions are highly conserved but intron positions are not. Cell, 24: 107-116.

17. Glover DM, Zaha A, Stocker AJ, Santelli MT, de Toledo SM \& Lara FJ S (1982). Gene amplification in Rhynchosciara salivary gland chromosomes. Proceedings of the National Academy of Sciences, USA, 79: 2947-2953.

18. Santelli RV, Machado-Santelli G, Pueyo MT, Navarro-Catapan LD \& Lara FJ S (1991). Replication and transcription in the course of DNA amplification of the C3 and C8 puffs of Rhynchosciara americana. Mechanisms of Development, 36: 59-66.

19. Paçó-Larson ML, de Almeida J C, Edstrom J E \& Sauaia H (1992). Cloning of a developmentally amplified gene sequence in the DNA puff $\mathrm{C} 4$ of Bradysia hygida salivary gland. Insect Biochemistry and Molecular Biology, 22: 439-446.

20. Wu N, Liang C, DiBartolomeis SM, Smith HS \& Gerbi SA (1993). Developmental progression of DNA puffs in Sciara coprophila amplification and transcription. Developmental Biology, 160: 73-84.

21. Winter CE, de-Bianchi AC, Terra WR \& Lara FJ S (1977). Relationships between newly synthesized proteins and DNA puff patterns in salivary glands of Rhynchos- ciara americana. Chromosoma, 61: 193206.

22. Winter $C E$, de-Bianchi AC, Terra WR \& Lara FJ S (1977). The giant DNA puffs of Rhynchosciara americana code for polypeptides of the salivary secretion. J ournal of Insect Physiology, 23: 1455-1459.

23. de-Almeida J C (1997). A 28-fold increase in secretory protein synthesis is associated with DNA puff activity in the salivary gland of Bradysia hygida (Diptera, Sciaridae). Brazilian J ournal of Medical and Biological Research, 30: 605-614.

24. Penalva LOF, Yokosawa J, Stocker A, Soares MA, Graessmann M, Orlando C, Winter C, Botella LM, Graessmann A \& Lara FJ S (1997). Molecular characterization of the C-3 DNA puff gene of Rhynchosciara americana. Gene, 193: 163-172.

25. Crouse HV (1968). The role of ecdysone in DNA puff formation and DNA synthesis in the polytene chromosomes of $\mathrm{S}$. coprophila. Proceedings of the National Academy of Sciences, USA, 61: 971-978.

26. Stocker AJ \& Pavan C (1974). The influence of ecdysterone on gene amplification, DNA synthesis and puff formation in the salivary gland chromosomes of Rhynchosciara hollaenderi. Chromosoma, 45: 295-319.

27. Amabis DC \& Amabis J M (1984). Effects of ecdysterone in polytene chromosomes of Trichosia pubescens. Developmental Biology, 102: 1-9.

28. Amabis DC \& Amabis J M (1984). Hormonal control of gene amplification and transcription in the salivary chromosomes of Trichosia pubescens. Developmental Biology, 102: 10-20. 